\title{
DYNAMIC ANALYSIS OF HISTORIC RAILWAY BRIDGES IN POLAND IN THE CONTEXT OF ADJUSTING THEM TO PENDOLINO TRAINS
}

\author{
K. GRĘBOWSKI* and M. ZIELIŃSKA \\ Department of Structural Mechanics and Bridge Structures \\ Faculty of Civil and Environmental Engineering \\ Gdansk University of Technology \\ ul. Narutowicza 11/12, 80-233 Gdansk, POLAND \\ E-mail: karol.grebowski@pg.gda.pl; monika.zielinska@pg.gda.pl
}

\begin{abstract}
The article presents the dynamic analysis of the historic railway bridge in Tczew as an example of the usefulness of such type of bridge for high-speed trains. The model of the bridge and the simulation of rolling stock passage was performed in SOFISTIK program. The scope of work includes experimental studies, the solution of the problem concerning the correct solution features of the dynamic model which takes into account the dependencies between the bridge, track and rolling - stock (RBT). The verification of the model was performed by comparing the results obtained on site during the passage of ET-22 locomotive and twenty (20) open goods wagons with the results obtained in the program for the identical type of rolling stock used to the simulation Pendolino train. Then, after the verification, the simulation of high-speed train passage was performed. The speed of the train passage varied from $150[\mathrm{~km} / \mathrm{h}]$ to the max. possible speed of $250[\mathrm{~km} / \mathrm{h}]$ which PENDOLINO train, approved for the simulation, may reach. Under the analysis of obtained results it was possible to define the conditions for adjusting the historic bridge to high-speed train passage.
\end{abstract}

Key words: dynamic analysis, modal analysis, historic bridges, high-speed trains.

\section{Introduction}

The term, high-speed trains, involves passenger transport at a speed exceeding $200 \mathrm{~km} / \mathrm{h}$. In Poland, there have been discussions on building high-speed railway lines for many years. However, all activities and plans are still in the preliminary feasibility study phase, and also the phase of yet undeveloped concept. The program of building high-speed railway lines, the first concepts of which appeared still in the 1990s, is one of the key elements in the modernization of the Polish railway bridges, aiming at renovating them and including them in the European railway area, the standards and quality of which make it possible to meet the present-day expectations of the society and economy as well.

The bridge-type structure approved for use and operation at high-speed rolling stock passage pursuant to the requirements shall satisfy:

- the requirement for Ultimate Limit State taking into account additional dynamic and fatigue effects caused by increased speed,

- the requirements for Serviceability Limit State which ensures railroad security and adequate passenger riding comfort, and also the requirements for life-span and durability,

- the requirements for adequate fixtures and fittings and the correctness of structural solutions.

\footnotetext{
* To whom correspondence should be addressed
} 
In relation to the above mentioned concept, in this study the analysis of the railway bridge in Tczew was conducted and presented as an example of usability of such type of bridges for high-speed trains.

For the purpose of this analysis, from among all spans of the bridge span no. 10 of the lowest loadcarrying capacity was selected. The span is composed of a double-track, single-span, steel, parabolic bridge of $128.60[\mathrm{~m}]$ span length. The analyses were to assess whether it is possible to adjust the structure to the speed of $250[\mathrm{~km} / \mathrm{h}]$ and provide grounds for preparing the potential modernization project.

In the case of bridges where trains pass through them at high speed, the dynamic coefficient fails to include the total gain in internal forces. Therefore, one shall perform dynamic calculations to evaluate whether in the structure too high acceleration of free vibration causing track instability is likely to occur, and perform measurements of stresses, dislocations, frequencies and modes of free vibrations, and measure the maximum dynamic effects of the bridge span.

The paper presents a method for modelling the dynamic interactions of the Pendolino train and the construction of historic bridges in Poland. Experimental studies were carried out on the railway bridge in Tczew to solve the problem concerning the correct solution features of the dynamic model which takes into account the relationship between the bridge, track and moving after the fleet. Numerical simulations were compared with the results obtained in the field conclusions that are tips for designers were formulated.

One of the principal work about railway was published in 2010 by Coenraad (2001). Dynamic analyses of railway bridge under trains were also studied by a lot of other authors, for example: Arvidsson et al. (2014), Cheng et al. (2001), André H. Jesus et al. (2014), Morassi and Tonon (2008), Calçada et al. (2002) and Yang and Yau (1997). Moreover, a lot of studies described the interaction between fast trains and bridges: Olmos and Asitz (2013), Lavado et al. (2014), He Xia and Nan Zhang (2005), Moreno Delgado and dos Santos (1997). The numerical simulations and mathematical models in the dynamical response of bridges under fast trains where presented for example by Van Nguyen et al. (2009), Shen-Haw Ju and Hung-Ta Lin (2013) and Kaliyaperumal et al. (2011). Even in Poland there is a big interest in fast speed trains by Klasztorny (2005), Klasztorny et al. (2002), Pyrzowski and Skabara (2003). On the other hand, the amount of research concerning high speed trains moving on a historical bridge is quite limited, compared with other bridges.

\section{Historical description}

At the beginning of the twentieth century, with the change of the axis of the station and reconstruction of the track, the railway bridge in Tczew was built. The bridge is located on $294.625 \mathrm{~km}$ line no. 009 Warsaw - Gdańsk Vistula River. The history of the bridge can be precisely reconstruct since 1939.

In 1939 the bridge was composed of nine spans. Spans no. 1, 2, 3 from Lisewo were made as a lattice of parallel stripes with a secondary suspending with length of $81.6[\mathrm{~m}]$. Spans no. 4, 5, 6, 7, 8, 9, with a total length of $133.88[\mathrm{~m}]$ and the theoretical range equal to $129.20[\mathrm{~m}]$, were made like multiple trusses with the main girder lens-shape. During the war in September 1939, spans no. 3, 4, 8 and 9 were damaged or even destroyed. Moreover, in this time pillars 3,8 and a foothold from Tczew were destroyed.

In 1941 the bridge was rebuilt and restored. The reconstruction consisted building a new pillar between the existing 3 and 4, repair of pillars 3 and 4 and replacement of the span no. 4 spans with a theoretical length equal $63.54[\mathrm{~m}]$. The new spans made as trusses with parallel stripes. In addition pillar no. 8 and a foothold from Tczew was rebuilt. In place of completely destroyed spans 8 and 9 a new spans were built with a theoretical range equal to $128.60[\mathrm{~m}]$, representing grates with parallel stripes. After completion the bridge consisted of 10 spans (Fig.1). 
1912

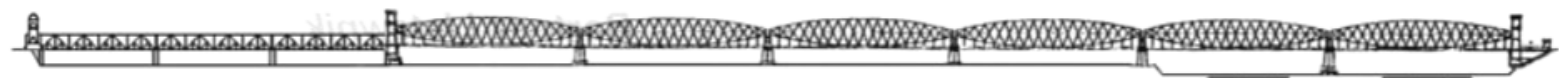

1940

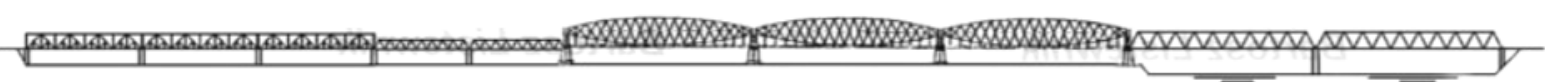

1947

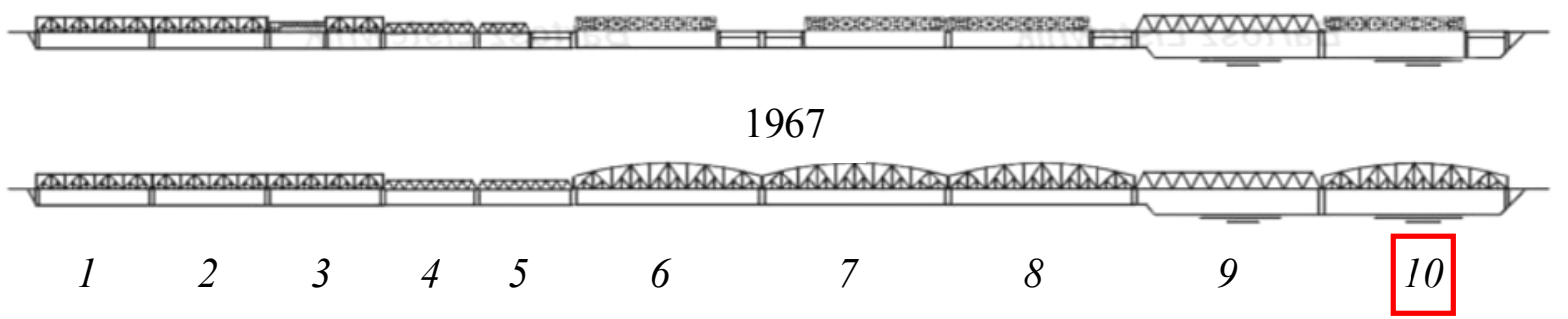

Fig.1. View of the historic railway bridge in Tczew.

In 1945, the bridge was destroyed again. Destructions were much more extensive and severe than in 1939. Spans were partially (no. 1,2,3,5,9,10) or even completely (no. 6,7,8) destroyed. The foothold from Tczew was destroyed. Every pillar was damaged to a greater or lesser extent.

The scope of the reconstruction included:

- making a foothold from Tczew,

- repair of bridge pillars and spans no. 1,2,3,5 and 9,

- execution of lattices with a theoretical length of $128.60[\mathrm{~m}]$, representing the upper belt trusses with secondary suspending of parabolic type.

The above-described range of renovation was completed in 1967 and has not changed to this day. The steel bridge is made of four types of lattice structures. A report assessing the technical condition of the bridge in January, February, March 2007 stated that parabolic span truss no. 10 has the smallest load capacity and endurance and it was chosen for a further study and analysis.

\section{Description of bridge span no. 10}

The bridge span no. 10 has the lowest load-carrying capacity. The bridge load-carrying structure is composed of cantilevered, truss, double-track span with passage along the lower chord. The span structure is based on a parabolic plan. The theoretical span length totals $128.60[\mathrm{~m}]$, calculation depth at midspan amounts to $20[\mathrm{~m}]$ and at piers $10[\mathrm{~m}]$. The node longitudinal length totals $6.43[\mathrm{~m}]$. All rods are welded and the node joints are riveted. The span is made of $18 \mathrm{G} 2 \mathrm{~A}$ steel.

The cross-beams are composed of welded, double-tee, steel beams of $6.43[\mathrm{~m}]$ in length. The joints between cross-beams and the lower chord are riveted. In the mid-section of cross-beams there are wind bracings of angle steel.

Girders are placed on abutments with the use of steel rocker and roller bearings. The bodies of abutments are solid concrete. The track is mounted on bridge sleepers.

The examination, measurements, studies and calculation analyses proved that in the current state, particular groups of bridge spans demonstrate diversified load-carrying capacity and refer to different load classes. The elements which limit the bridge load-carrying capacity is the deck subjected to the highest dynamic load caused by rolling stock passing through, and also some elements of the main parabolic girders. The lower girders, the deck and also the bearings show, apart from local corrosion centres, the 
effects of anti-corrosion protection loss over the whole surface. The most significant and demanding the most attention corrosion damages include the corrosion of: riveted joints cross-beam - main girder (lower chord), cross-beam - stringer, longitudinal cross braces and girder posts, sleeper fastenings, bearings on piers. Taking into account the safety of the structure, the corrosion of riveted joints poses the most significant threat.

In 2011, the bridge was repaired; the cracks in cross-beams were removed, some changes in the bridge construction were introduced, and the entire load-carrying system of the bridge was modernized (Fig.2).

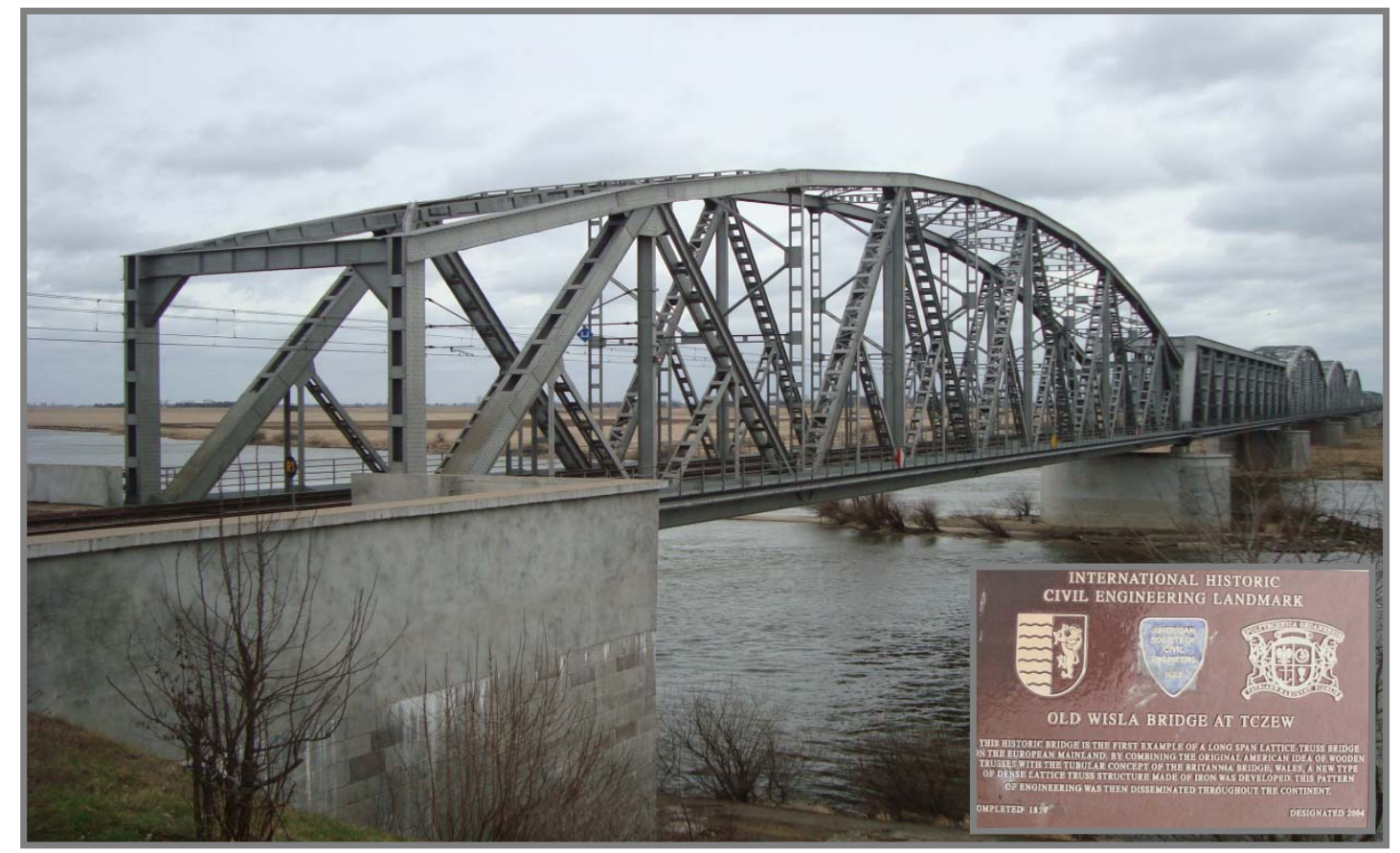

Fig.2. View of the historic railway bridge span no. 10 in Tczew,

\section{Bridge numerical model}

The bridge span model was made with the use of SOFISTIK program. In order to reconstruct correctly the structure in the calculation model three types of elements were used:

- beam element (BEAM),

- truss element (TRUSS),

- quad element (QUAD).

The beam element was used to model the whole bridge, whereas the quad element was used to define the concrete deck and the additional structure situated in the front and in the back of the bridge where the train was placed. The FEM model was made pursuant to the bridge project documentation. The parameters of the model were updated as per measurement data obtained on site.

The model of the structure has 3 degrees of freedom ( 3 displacements towards UX, UY, UZ). The number of elements generated in the program totals 3189, whereas the number of generated nodes totals 2436. The structure was supported on one side by sliding supports and on the other by non-sliding supports (Fig.3). 

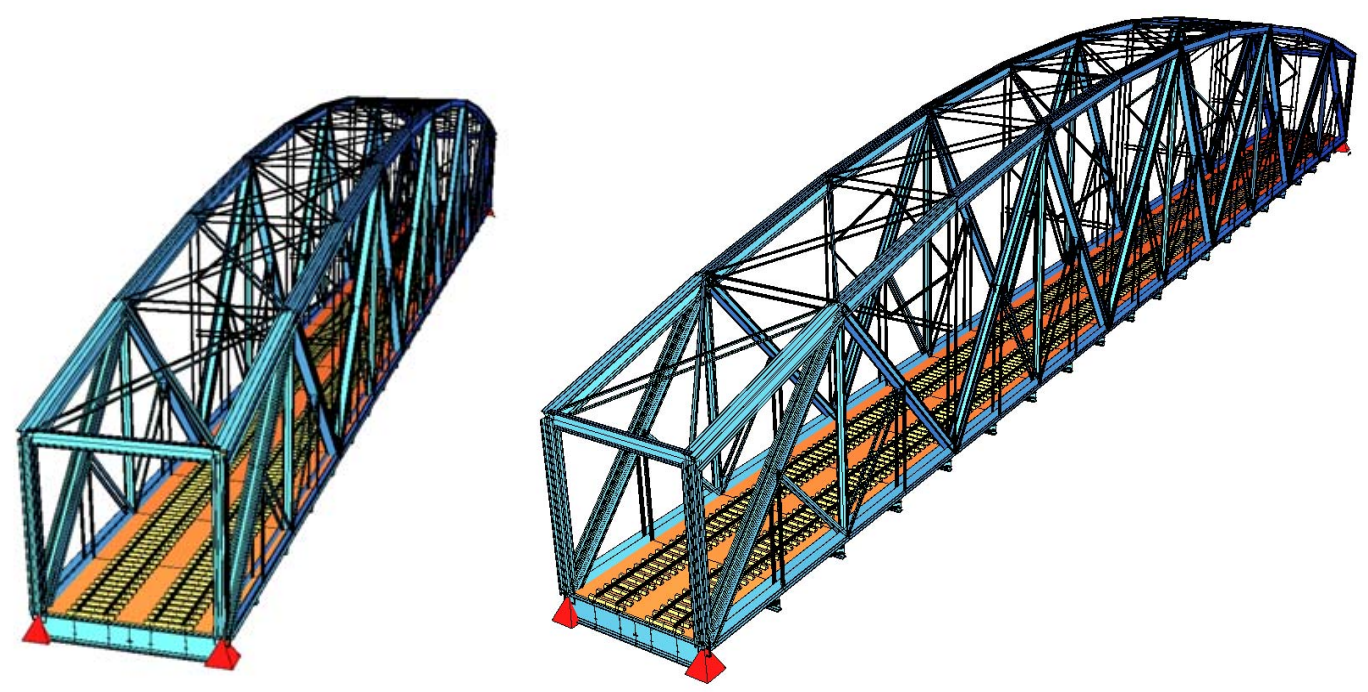

Fig.3. Numerical model of span no. 10 of the railway bridge in Tczew.

With the use of modal analysis it was possible to determine the eigenfrequencies and the related modes of vibrations (Fig.4). From the theoretical viewpoint it consists in solving an individual problem (4.1)

$$
\left[[K]-\omega_{i}^{2} \cdot[M]\right] \cdot\left\{\phi_{i}\right\}=\{0\}
$$

where $[K]$ - stiffness matrix, $[M]$ - mass matrix, $\omega_{i}^{2}$ - eigenfrequency, $\left\{\phi_{i}\right\}$ - eigenvector (mode of vibrations).
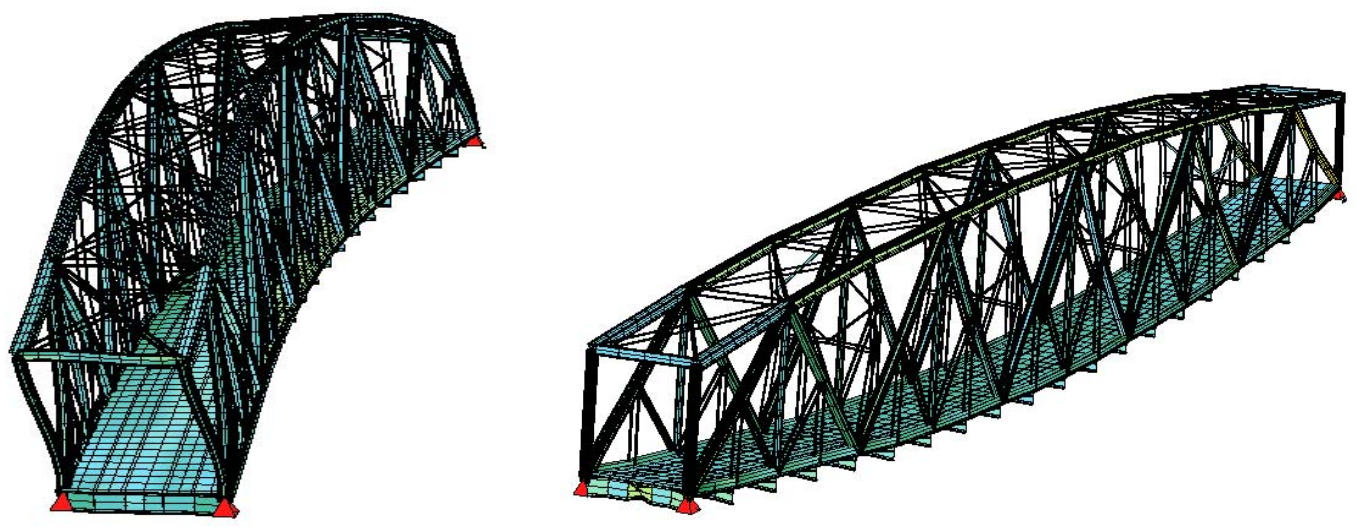

Fig.4. Modes of individual vibrations for $1.17[\mathrm{~Hz}]$ (on the left) and $2.07[\mathrm{~Hz}]$ (on the right).

The dynamic analysis indicated that in the range of $1.17[\mathrm{~Hz}]$ to $3.88[\mathrm{~Hz}]$ there are at least 10 eigenfrequencies. Such a significant number of eigenfrequencies is natural for the spatial structure made of repeatable elements. The calculations proved that the first flexural horizontal mode occurs for eigenfrequencies of $1.17[\mathrm{~Hz}]$, whereas the first flexural vertical mode for eigenfrequencies of $2.07 \mathrm{~Hz}]$. 


\section{Verification of the model}

In order to define the dynamic characteristics of the structure, the dynamic trials were made. The obtained results were to enable defining the span dynamic excitation and verifying the calculation model adopted for the analysis. The correctness of the performed bridge model was verified through comparing the results measured on site on the bridge during the actual passage of ET-22 locomotive and twenty (20) open goods wagons with the results obtained from the bridge and rolling stock model performed in SOFISTIK program.

The measurements were performed in 2013. The rolling stock model was made in the same manner as the PENDOLINO train model. The locomotive and wagons were formed as the beam element with proper section and specific weight and shape. Each axis was replaced by a set of strings of specific stiffness which transfer the weight of the whole section of the train onto the bridge. The wagons were connected with each other and with the locomotive by a truss element, which enabled them to operate independently.

Below there is a numerical model of the locomotive and wagons adopted to determine the correctness of the passage and the operation of the whole structure of the truss span. The direction of the passage was defined as from Tczew station to Lisewo station. The same direction was selected for the freight train while performing measurements in situ (Fig.5).

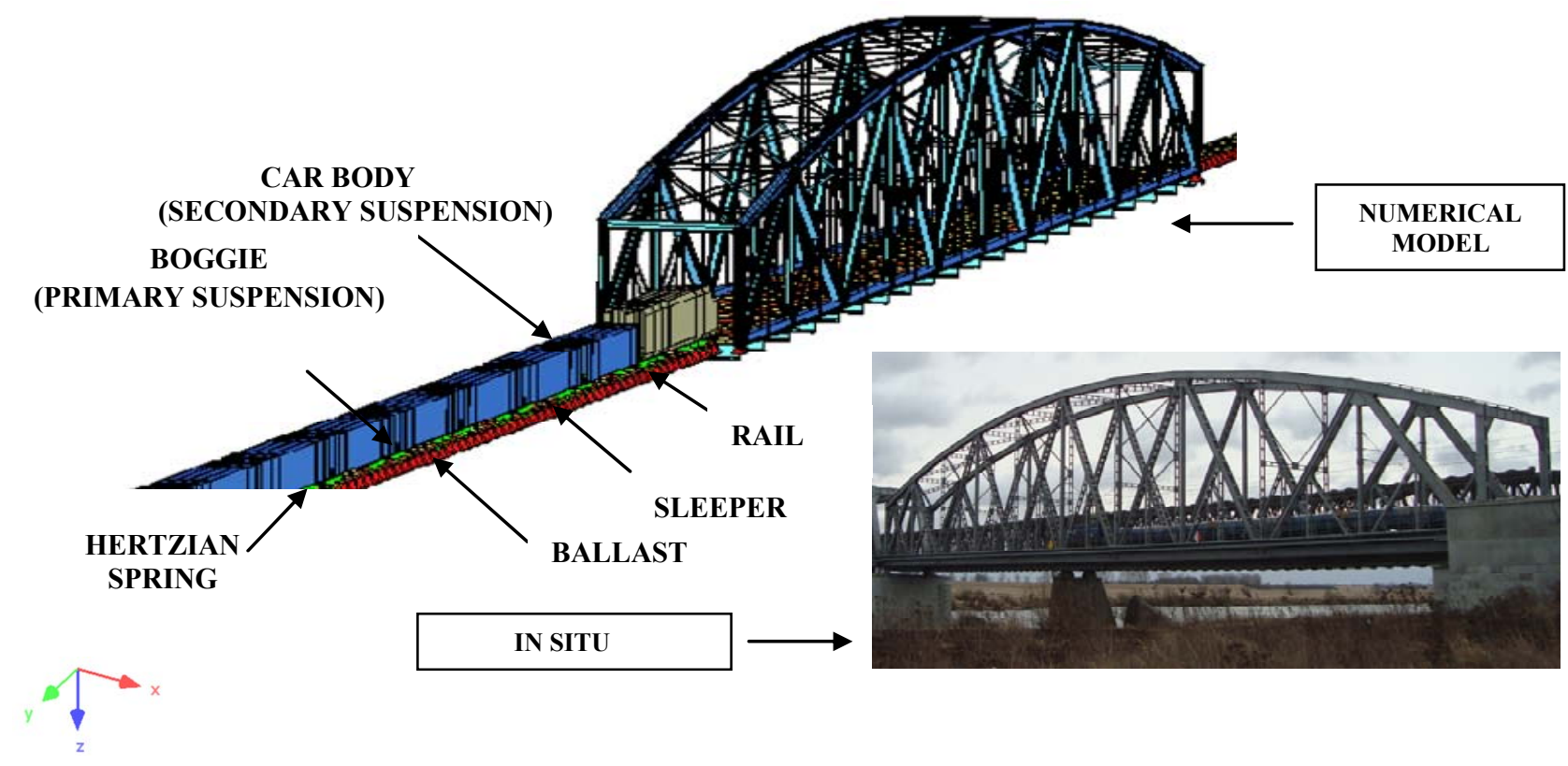

Fig.5. Verification of span model and rolling stock passage.

The total weight of the train amounted to approx. 1560 tons, and the total length was $300[\mathrm{~m}]$. The passage speed totalled approx. $30[\mathrm{~km} / \mathrm{h}]$. The calculations were made for the passage time of 50 [sec.] with integration step every $0.01[\mathrm{~s}]$.

Under the results obtained on site and the results from SOFISTIK program we can conclude that the numerical model of the bridge and rolling stock was performed correctly. The maximum deflection in $1 / 2$ span length measured on site amounts to $41.8[\mathrm{~mm}]$, whereas the deflection obtained during calculations amounts to $43.87[\mathrm{~mm}]$. It results from the fact that the difference between the two experimental deflections totals 4.96 [\%], which is equivalent to the fact that the model of the bridge and the rolling stock reflects correctly the train passage and the operation of the whole structure.

Also a comparison of normalized amplitude FFT results, the exciting force of the train in the domain frequency of field examinations $(1.48[\mathrm{~Hz}])$ and numerical simulations $(1.50[\mathrm{~Hz}])$ are practice the same. 
Under the results of the bridge eigenfrequency it is also possible to assume that the bridge and the rolling stock calculation model was performed correctly since within the time period of $5[s]$ of the bridge free vibrations totalled 10 which equals the frequency of $2[\mathrm{~Hz}]$. The recorded free vibrations of the structure amounting to $2[\mathrm{~Hz}]$ correspond to the calculation eigenfrequency of $2.07[\mathrm{~Hz}]$ for both the results obtained on site and the results from the program (Fig.6).

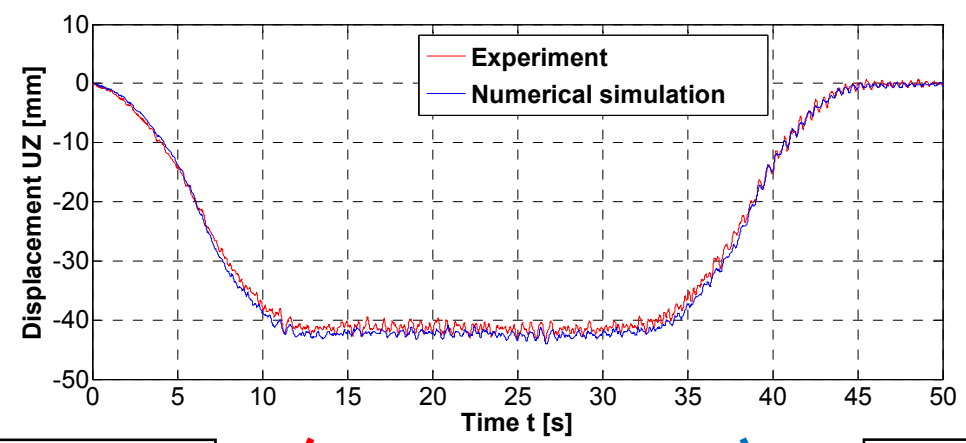

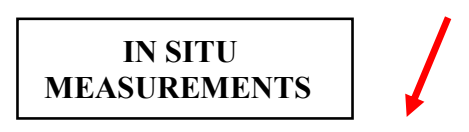

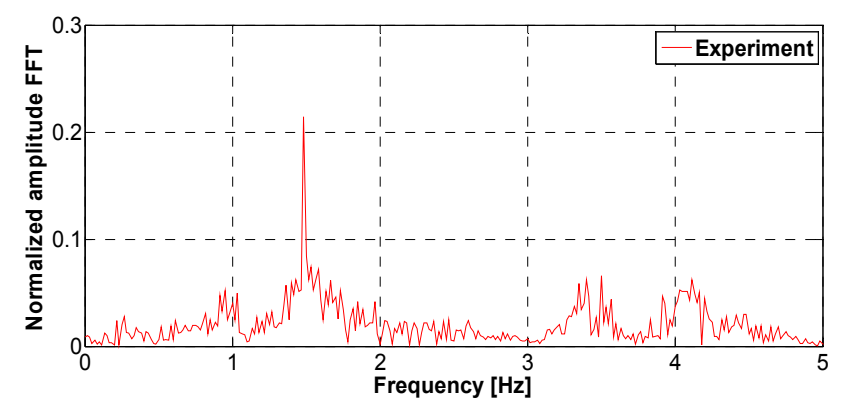

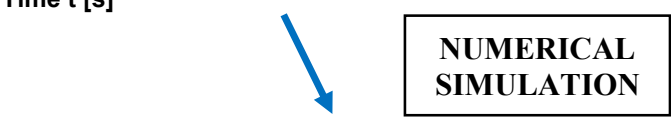

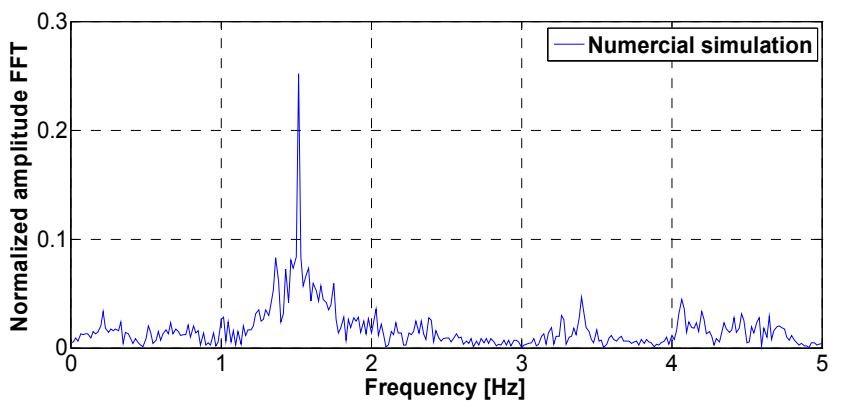

Fig.6. Comparison of displacement results in the domain of field examinations and numerical simulations. Comparison of normalized amplitude FFT results for the exciting force of the train in the domain frequency of field examinations and numerical simulations.

\section{Dynamic analysis of bridge span subjected to the load of pendolino train}

The dynamic calculations were performed using procedures taking into account complex relations between track-bridge-rolling stock. A high-speed train passing through the railway bridge generates in the load-bearing structure quick gain in stresses, distortions and vibrations which are included in the statistic calculations by applying the dynamic coefficient. However, when a particular mass is moving along the bridge span at high speed, the dynamic coefficient may not cover the total gain in forces and stresses. Then it is advisable to carry out the dynamic analysis which will reflect the reaction of the structure to the changing dynamic load.

In the RBT model (track-bridge-rolling stock) the dynamic analysis was conducted on a quasisymmetry plane coinciding with the line going through the bridge centre of gravity. The calculations involved the following parameters: quick-change running configuration of elements, supercritical damping and non-linear physical elements such as rails, sleepers, and ballast. The train load was modelled in the form of the rolling stock load transferred to a track with the use of a set of sprung bogie trucks, in this case springs replacing the axial load of the train set on rails, sleepers, and ballast (Fig.7). 


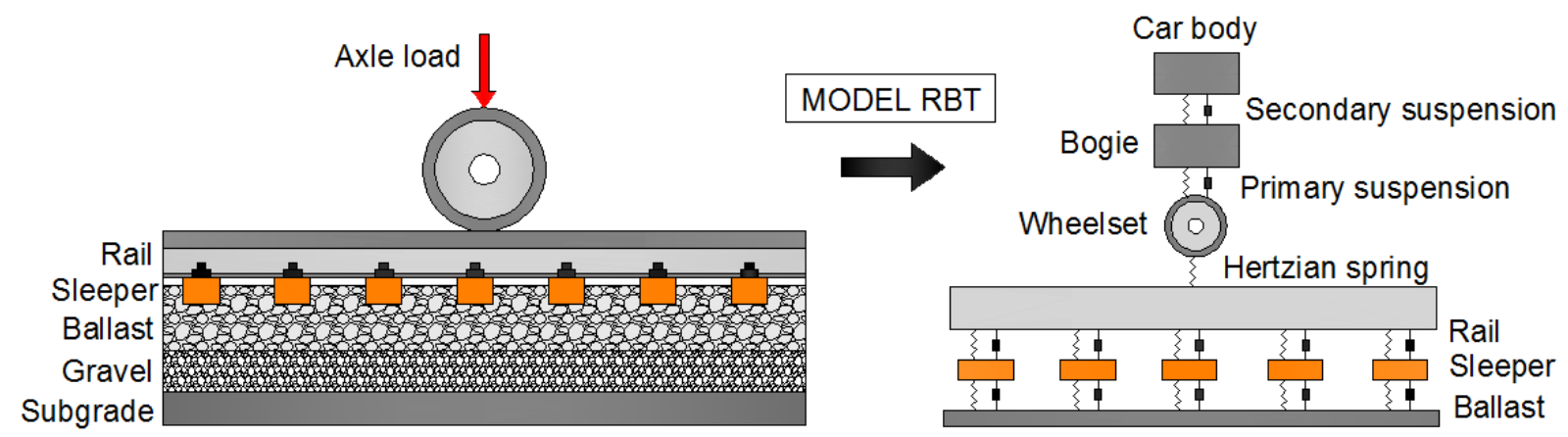

Fig.7. Scheme of relations between track-bridge-rolling stock (Esvels Coenraad, 2001).

During the structure calculations, under the method of model analysis, the lowest frequency of the span vertical free vibrations was determined, which amounts to $2.07 \mathrm{~Hz}$. The purpose of further calculations was to verify the behaviour of the viaduct span at high speed train passage of up to $250[\mathrm{~km} / \mathrm{h}]$. Displacements, stresses and the related accelerations generated in the load-carrying structure by the passing rolling stock change as a result of quick gain in load and inertia reaction (damping) of subsequent loads approximately equal to the wagon length. Therefore, as a result of wheel load variability arising from the imperfection of the track or railway vehicle, the dynamic load can very easily excite the structure and, in some circumstances, induce resonance.

The mathematical and physical modelling of the track-bridge-rolling stock system was divided into subordinate systems including the bridge structure, sprung load from the rolling stock, rail, sleepers and ballast (Fig.8). The motion equation adopted for calculations including the above mentioned subordinate systems take the following form Eq.(6.1)

$$
\begin{aligned}
& B_{0} \ddot{q}_{0}=F_{0}, \\
& B_{1} \ddot{q}_{1}+\left(\kappa K_{1}+C_{a}\right) \dot{q}_{1}+K_{1} q_{1}=F_{1}, \\
& B_{2} \ddot{q}_{2}=F_{2}, \\
& B_{3} \ddot{q}_{3}+\kappa K_{3} \dot{q}_{3}+K_{3} q_{3}=F_{3}
\end{aligned}
$$

where: $q_{o}, q_{1}, q_{2}, q_{3}$ - are sub-vectors of generalized coordinates; $B_{o}$ - inertia matrix of sprung mass subsystem; $B_{1}, K_{1}$ - inertia and stiffness matrix of rail sleeper; $C_{a}$ - damping matrix; $\kappa$ - retardation time for steel; $B_{2}$ - inertia matrix of sleepers; $B_{3}, K_{3}$ - inertia and stiffness matrix of steel load-carrying bridge structure; $F_{o}, F_{1}, F_{2}, F_{3}$ - sub-vectors of generalized loads.

The bridge and train model including the RBT model were developed in SOFISTIK program. The rolling stock is composed as a set of beams of specific section and specific weight $380[t]$. Particular wagons with drive units were connected with each other with the use of truss elements responsible for extending and contracting, which makes all rolling stock wagons operate independently. The locomotive and wagons axial load was replaced by springs of specific stiffness. 


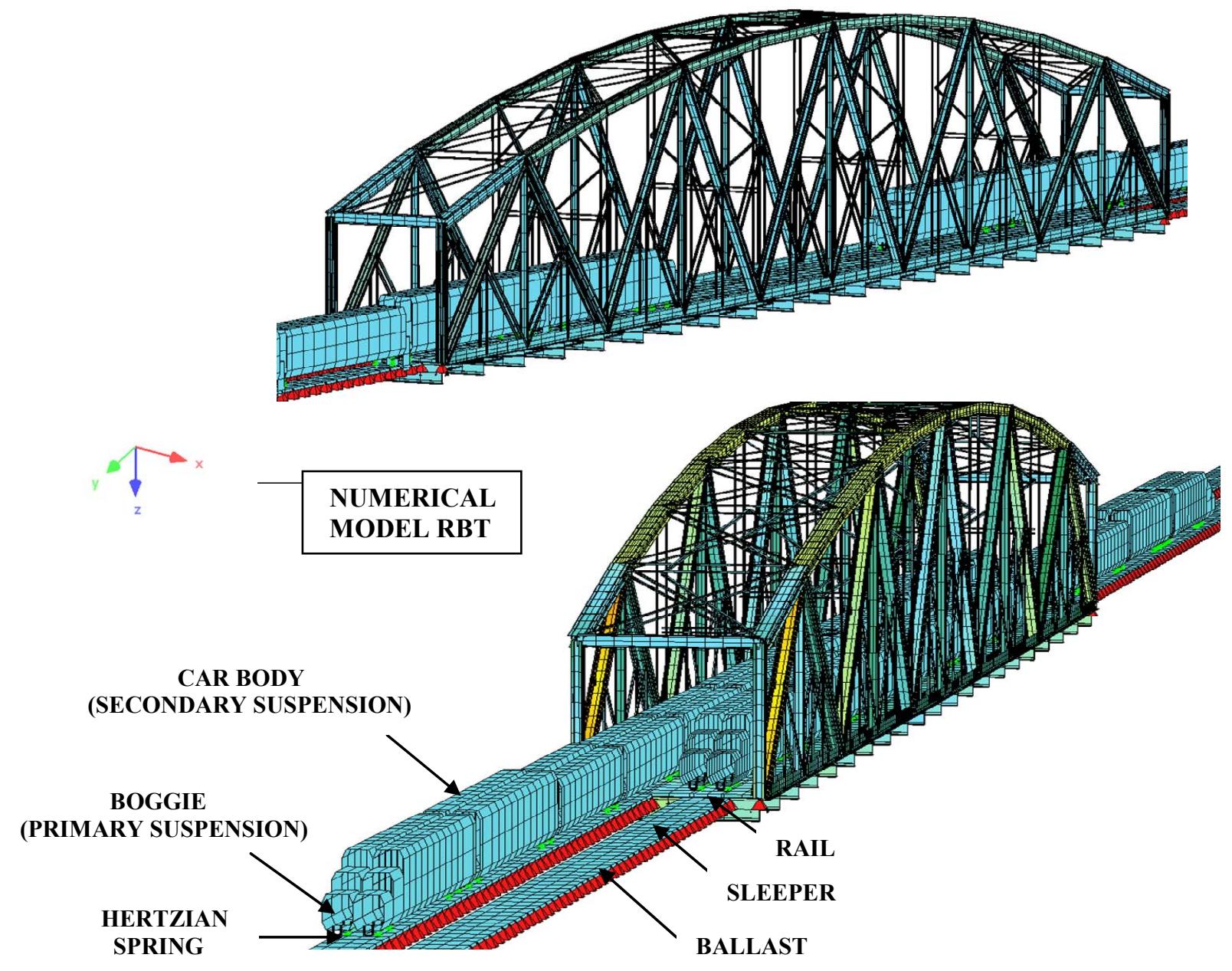

Fig.8. Numerical simulations of PENDOLINO train passage.

Spring spacing is equal to the standard rail spacing and amounts to 1435 [mm]. On both sides of the bridge span there is an additional slab structure of $300[\mathrm{~m}]$ in length, $2.5[\mathrm{~m}]$ in width and $0.3[\mathrm{~m}]$ thick. The structure is supported at every point of the slab element and is not prone to the train passage, and is not taken into account at the results analysis either. At the rolling stock modelling it is important to define the spring rate of the bogie truck which moves along the bridge span. If the spring rate is too big, the train will cause bigger vibrations of the bridge during the train passage. Therefore, the shock absorption of the rolling stock shall be accepted as per the real stiffness of the rolling stock scheduled for use. sets (Fig.9).

The calculations were performed for the most adverse load at the passage of two high-speed train 


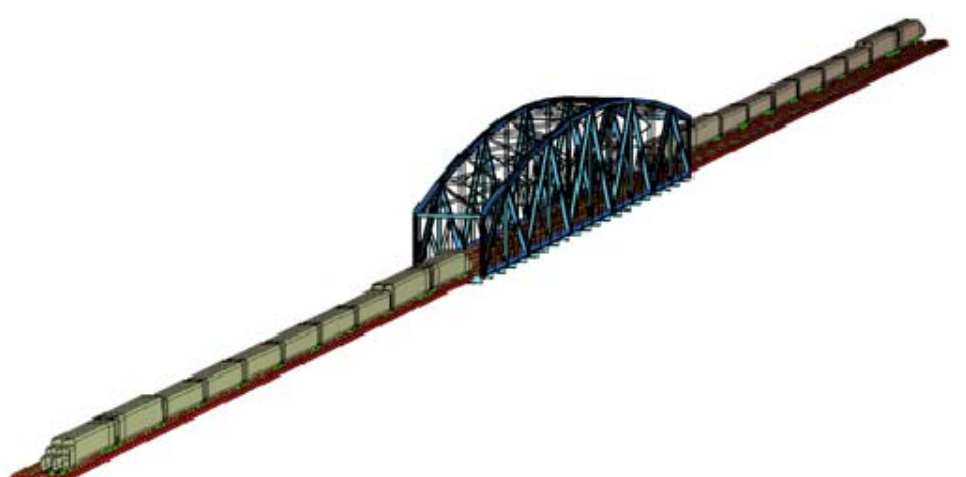

Fig.9a. The train at speed of $250[\mathrm{~km} / \mathrm{h}]$ in $0[\mathrm{~s}]$.

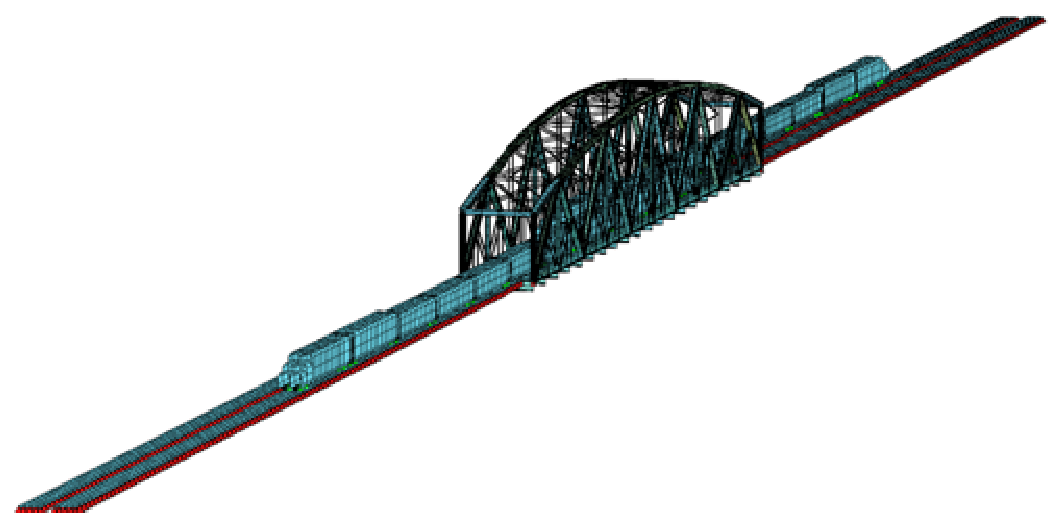

Fig.9b. The train at speed of $250[\mathrm{~km} / \mathrm{h}]$ in $1[\mathrm{~s}]$.

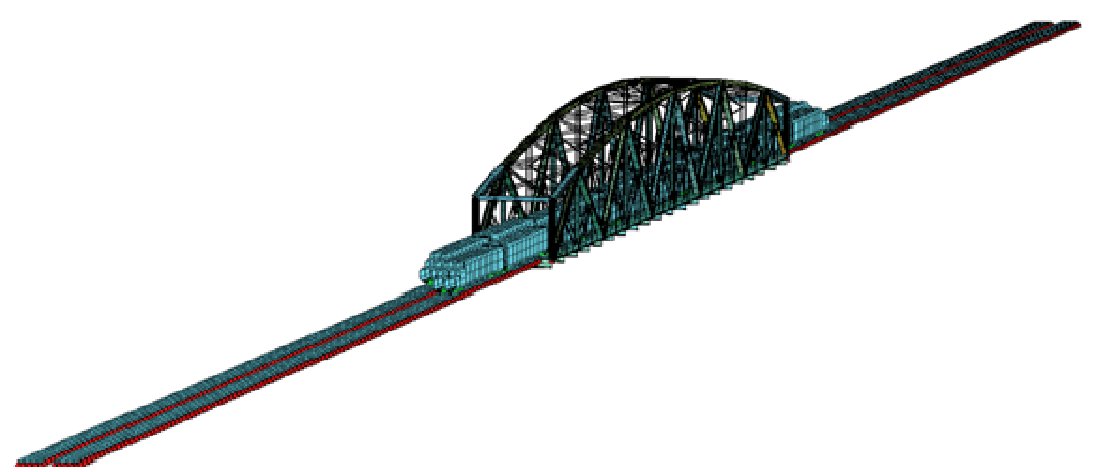

Fig.9c. The train at speed of $250[\mathrm{~km} / \mathrm{h}]$ in $2[\mathrm{~s}]$.

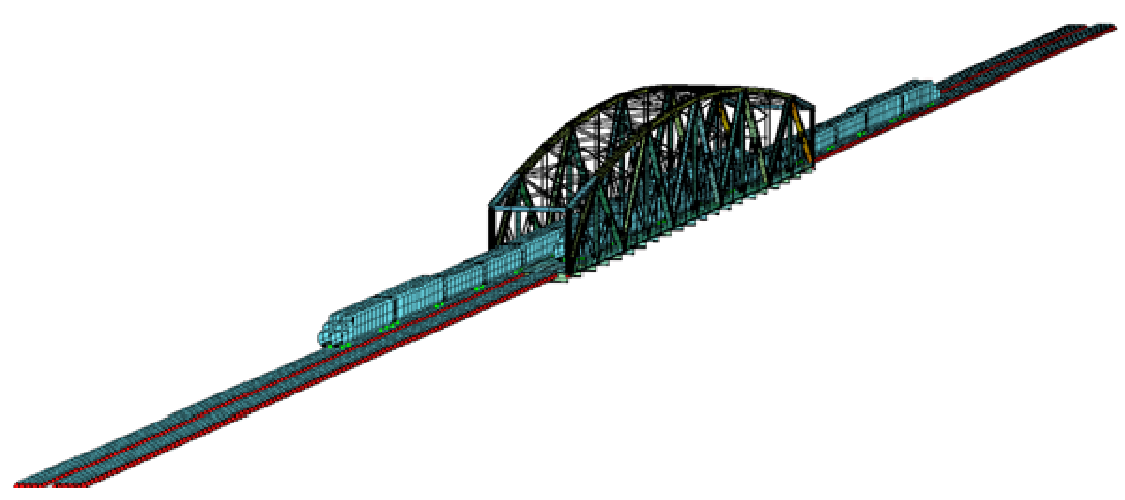

Fig.9d. The train at speed of $250[\mathrm{~km} / \mathrm{h}]$ in $3[\mathrm{~s}]$. 
The most important parameters of the calculations - passage direction: Tczew-Lisewo LisewoTczew, the lowest speed $150[\mathrm{~km} / \mathrm{h}]$, the highest speed $250[\mathrm{~km} / \mathrm{h}]$, range of speed change $10[\mathrm{~km} / \mathrm{h}]$, total mass $2 \times 380[t]$, axial thrust on bridge span $16[t]$, time of passage $10[\mathrm{~s}]$, integration step $0.001[\mathrm{~s}]$. The results of calculations were measured at $1 / 2$ bridge span at lower chord - nodes 141, 441, 741 (Fig.10).

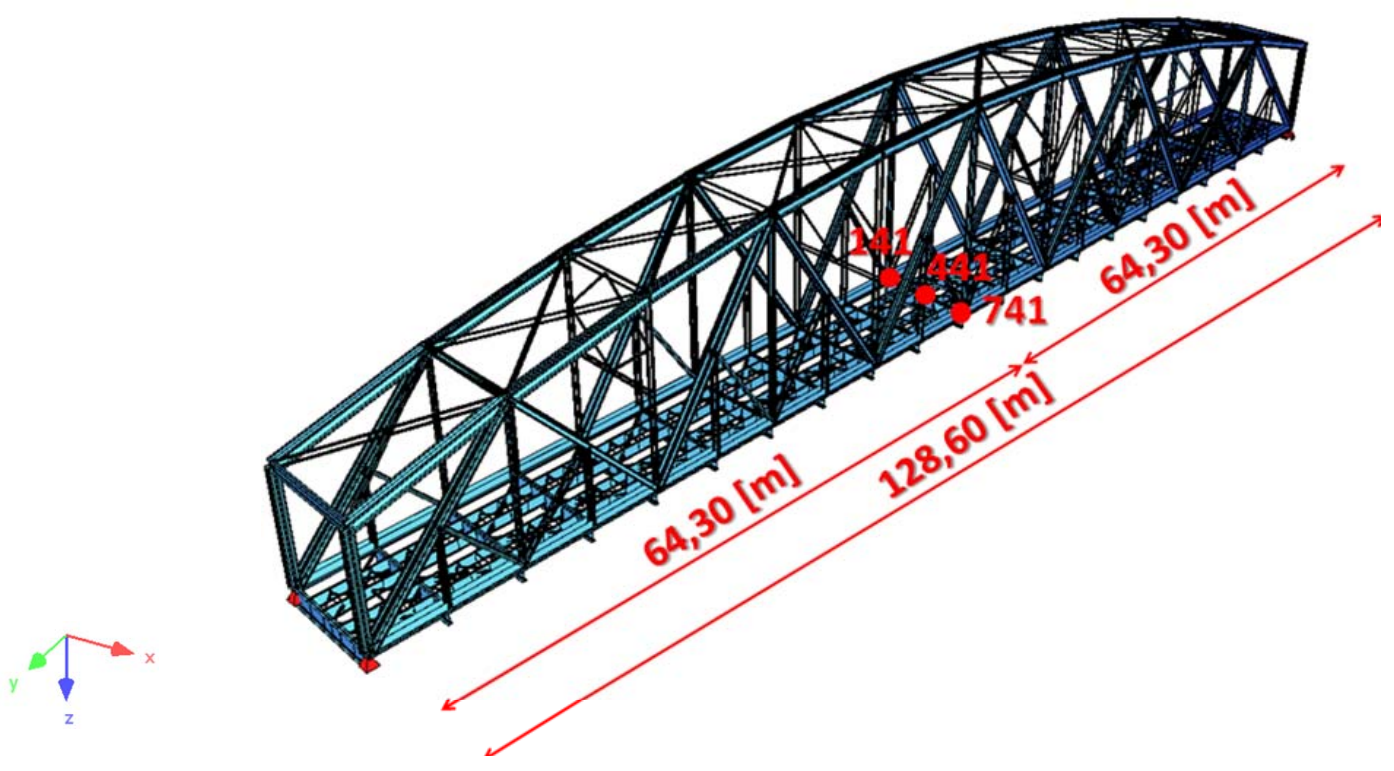

Fig.10. Scheme of measurement points at $1 / 2$ bridge span.

\section{Calculation results}

Below there are the results obtained from the numerical simulation of the PENDOLINO train passing through the railway bridge in Tczew (Figs 11-14).
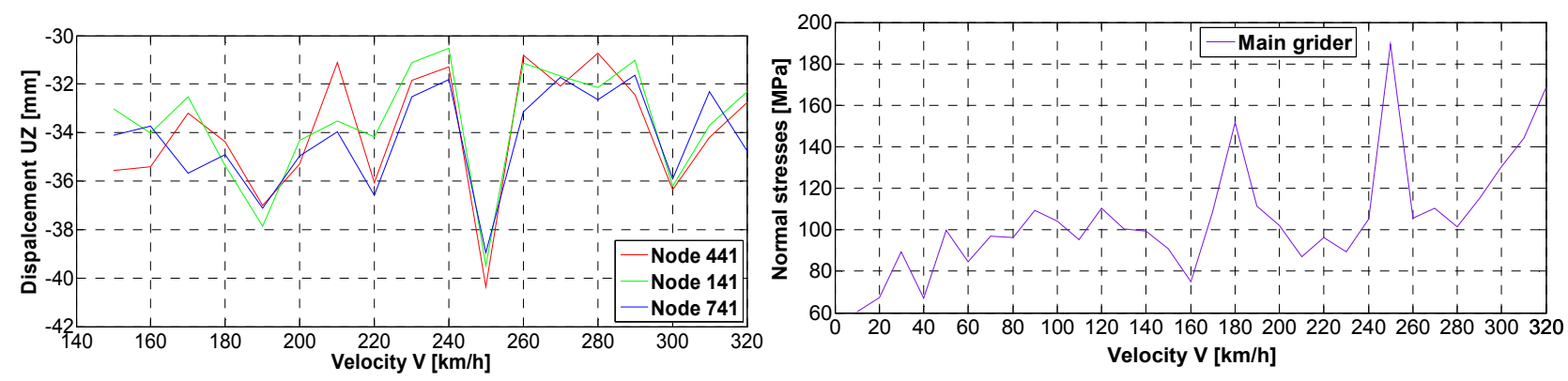

Fig.11. Diagram of displacements Uz $[\mathrm{mm}]$ and stresses $\sigma[\mathrm{MPa}]$ in the domain of speed at $1 / 2$ bridge span. 

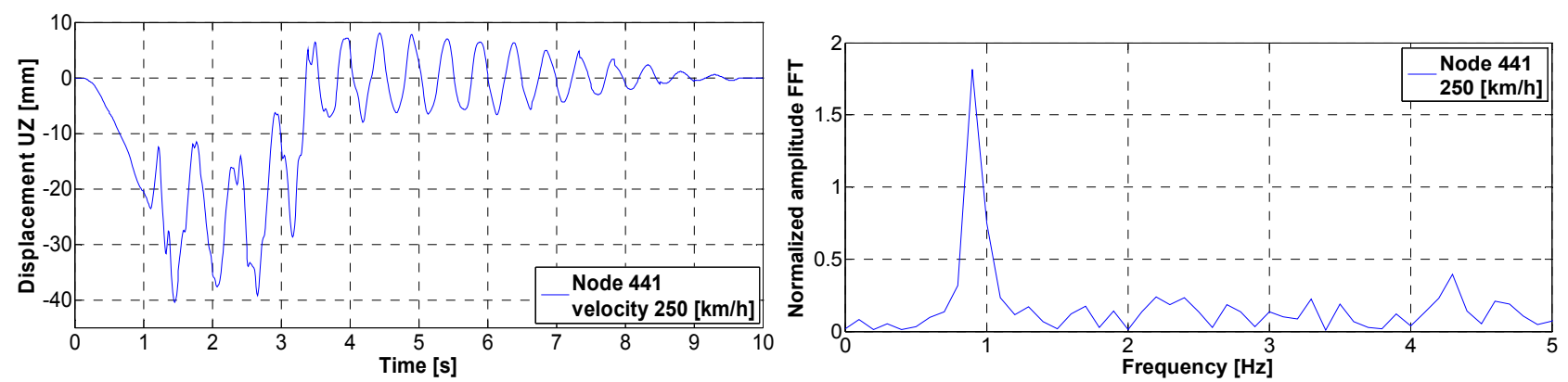

Fig.12. Diagram of displacement $\mathrm{Uz}[\mathrm{mm}]$ in the domain of time at $1 / 2$ bridge span for node 441 . Diagram of normalized amplitude FFT the exciting force of the train in the domain of frequency.
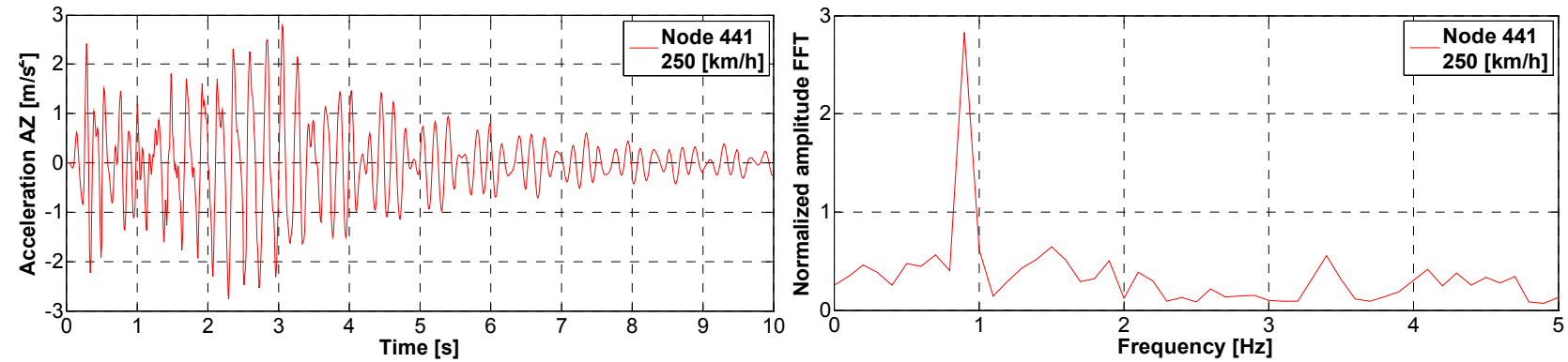

Fig.13. Diagram of accelerations $\mathrm{Az}\left[\mathrm{m} / \mathrm{s}^{2}\right]$ in the domain of time at $1 / 2$ bridge span for node 441 . Diagram of normalized amplitude FFT the exciting force of the train in the domain of frequency.
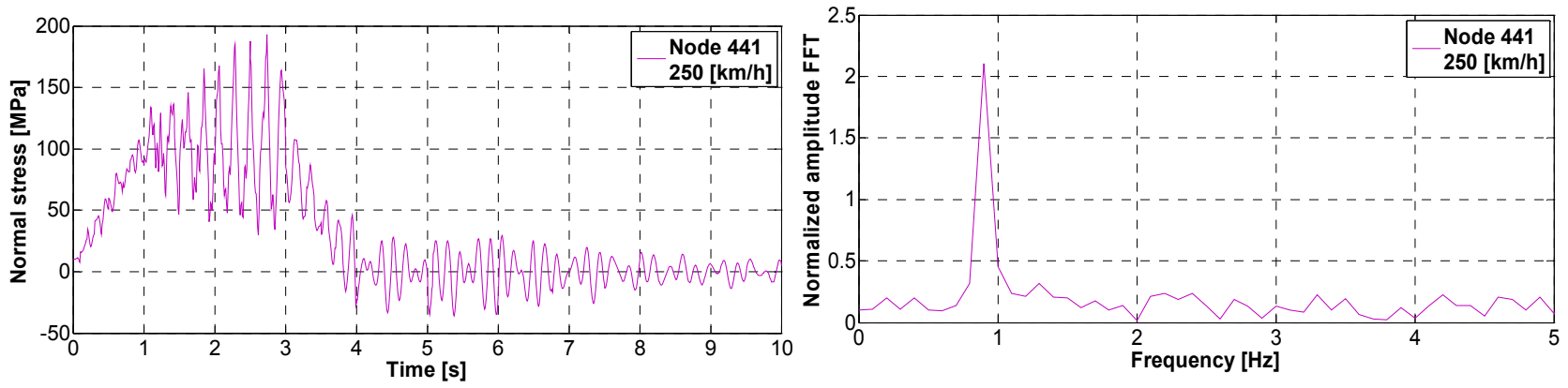

Fig.14. Diagram of stresses $\sigma$ [MPa] in the domain of time at $1 / 2$ bridge span for node 441 . Diagram of normalized amplitude FFT the exciting force of the train in the domain of frequency

\section{Final conclusions}

The subject matter of this study is the analysis of $128.6[\mathrm{~m}]$ span steel arch bridge in a sequence of the railway bridges in Tczew, over the Vistula River. The dynamic analysis of the bridge was carried out in order to verify the possibility of adjusting the structure to high-speed trains. The modal analysis indicated that the first 10 modes of bridge free vibrations fall within the range of 1.17 [Hz] to 3.88 [Hz]. The bridge vibrations caused by both the single train passage and two trains passage at the same time are dominated by two modes of free vibrations: third (flexural related to vertical vibrations) and first (flexural on a horizontal 
plane). The first flexural horizontal mode is characterized by vibration frequency of 1.17 [Hz], whereas the third mode $2.07[\mathrm{~Hz}]$.

The measurement data collected on site prove that the numerical model of the bridge and the rolling stock was performed correctly. The maximum displacement at $1 / 2$ span length measured on site amounts to $41.8[\mathrm{~mm}]$, whereas the displacement obtained as a result of calculations amounts to $43.87[\mathrm{~mm}]$. Consequently, the difference between both extreme displacements amounts to 4.96 [\%]. Moreover, within 5 $[s]$ the time period of the bridge free vibrations amounted to 10 , which is equal to the frequency of $2[\mathrm{~Hz}]$. The recorded free vibrations of the structure of $2[\mathrm{~Hz}]$ frequency correspond to eigenfrequency of $2.07[\mathrm{~Hz}]$ obtained during calculations, for both the results obtained on site and the results from the program. The constructed FEM model correctly simulates the bridge and train dynamics.

The maximum vertical displacements for the simultaneous passage of two train sets amounts to $\delta_{\text {real }}$ $40.5[\mathrm{~mm}]$. The value fails to exceed the admissible displacement which at span length of $128.6[\mathrm{~m}]$ amounts to $\delta_{\text {limit }} 64.3[\mathrm{~cm}]$. On the grounds of the usability limit the values of vibration accelerations are very important. The accelerations higher than the limit value of $\mathrm{A}_{\text {limit }} 3.5\left[\mathrm{~m} / \mathrm{s}^{2}\right]$ as per the Eurocode failed to occur while conducting the dynamic analysis of nodes and bridge span. At acceleration values of $7\left[\mathrm{~m} / \mathrm{s}^{2}\right]$ there is a risk of loosening the ballast. The maximum values of vibration accelerations for the simultaneous passage of two train sets amount to $\mathrm{A}_{\text {real }} 2.9\left[\mathrm{~m} / \mathrm{s}^{2}\right]$. On the grounds of the load-carrying capacity limit the values of stresses in elements limiting the load-carrying capacity are important which, in this case, is the deck subjected to the highest dynamic load. In the case of the load generated by the passage of two train sets the extreme stresses amount to $\sigma_{\text {real }} 189.4$ [MPa]. The values fail to exceed the admissible value of stresses for $18 \mathrm{G} 2 \mathrm{~A}$ steel (S355) which in three-dimensional stress pattern amounts to $\sigma_{\text {limit }} 308$ [MPa]. And the normalized amplitude FFT for the exciting force of the high speed train amounts 0.97 [Hz].

An important part of the numerical analysis of old riveted bridges takes into account the cyclical nature of the trips. Numerical simulations have shown that in the case of a single crossing of the bridge load we get incorrect results, because a very important factor is included which is the fatigue of the structure. In the present case, we can see that the bridge during a single journey meets the conditions of the ultimate limit state and serviceability, while in the case of cyclic passages in succession a slow destruction of the span is predictable. At about 4,000 cycles ULS and SLS conditions are exceeded which may lead to disaster.
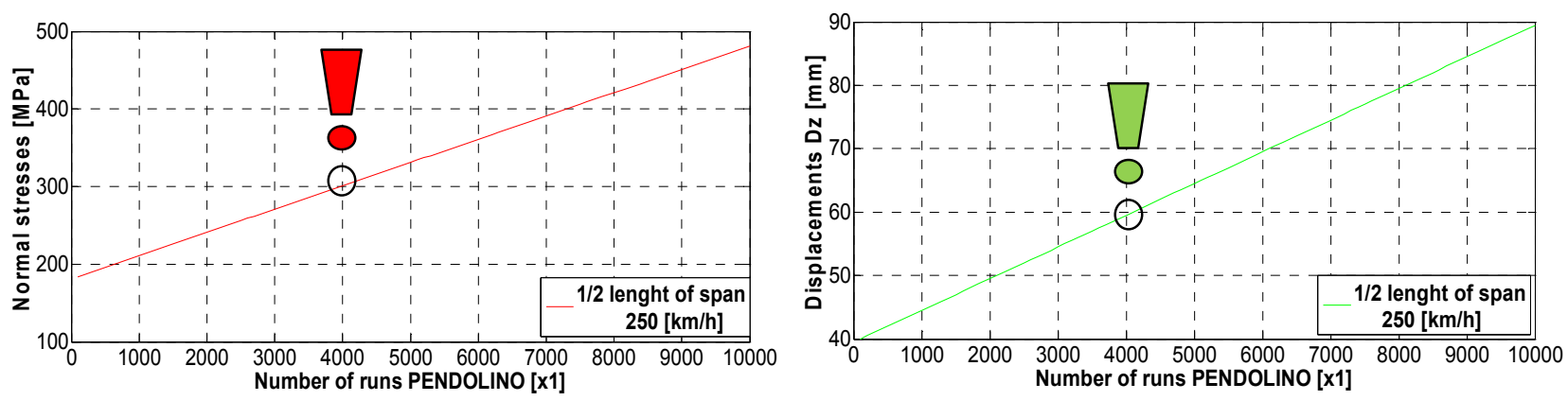

Fig.15. The results of stresses and displacements of cyclic Pendolino trains pass.

At designing and modernizing the railway bridge in Tczew in relation to its adjustment to high-speed train passage it is necessary to carry out the analysis of periodical passage of the train, and take into consideration the fatigue of the structure (mainly riveted joints of particular load-bearing elements). In the design process there are no procedures which take into account the dynamic loads caused by passing trains at high speed. The use of the identified load model will allow the design phase or upgrade to increase safety of railway bridges. 


\section{Nomenclature}

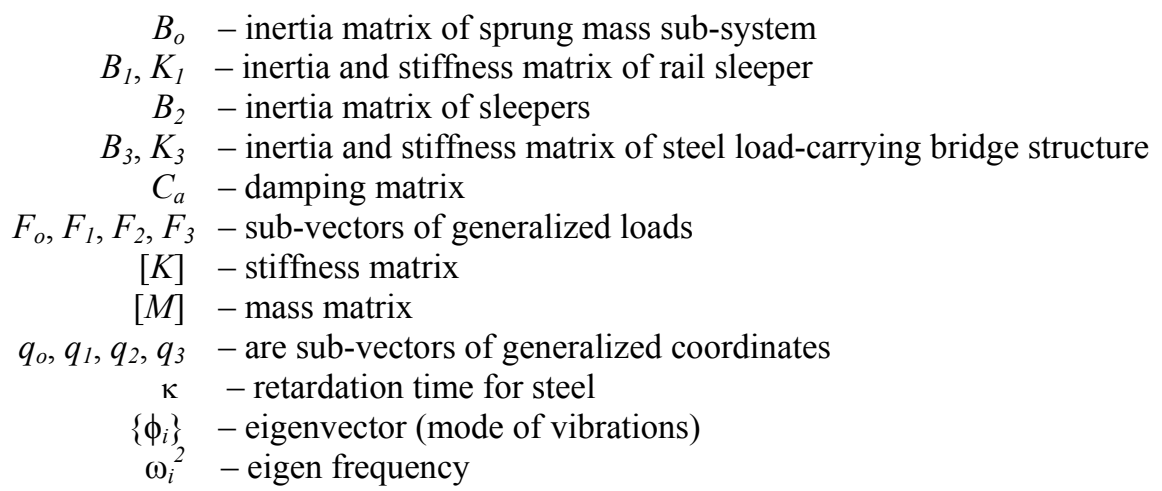

\section{References}

Arvidsson T., Karoumi R. and Pacoste C. (2014): Statistical screening of modelling alternatives in train-bridge interaction systems. - Engineering Structures, vol.59. pp.693-701.

Calçada R., Cunha A. and Delgado R. (2002): Dynamic analysis of metallic arch railway bridge. - J. Bridge Eng., vol.7, No.4, pp.214-222.

Cheng Y.S., Au F.T.K. and Cheung Y.K. (2001): Vibration of railway bridges under a moving train by using bridgetrack-vehicle element. - Engineering Structures, vol.23, No.12. pp.1597-1606.

Esveld C. (2001): Modern Railway Track Second Edition. - MRT - Productions, Delft.

Extract from detailed project documentation (2007). Repair of the bridge in Tczew over the Vistula River km 294.625 Part 3DP/M, May 2007

He Xia and Nan Zhang (2005): Dynamic analysis of railway bridge under high-speed trains. - Computers and Structures, vol.83, No.23-24, pp.1891-1901.

Jesus A.H., Dimitrovová Z. and Manuel A.G. Silva (2014): A statistical analysis of the dynamic response of a railway viaduct. - Engineering Structures, vol.71, pp.244-259.

Jose Olmos M. and Miquel Asitz A. (2013): Analysis of the lateral dynamic response of high pier viaducts under high speed train. - Engineering Structures, vol.56, pp.1384-1401.

Kaliyaperumal G., Imam B. and Righiniotis T. (2011): Advanced dynamic finite element analysis of a skew steel railway bridge. - Engineering Structures, vol.33, No.1, pp.181-190.

Klasztorny M. (2005): The Dynamics of Beam Bridges Loaded High-Speed Trains. - Warsaw: WNT.

Klasztorny M., Maślecki K., Machelski Cz. and Podwórna M. (2002): Analysis of the dynamic range of steel bridges loaded trains moving at high speeds. - Wroclaw: PW.

Lavado J., Doménech A. and Martínez-Rodrigo M.D. (2014): Dynamic performance of existing high-speed railway bridges under resonant conditions following a retrofit with fluid viscous dampers supported on clamped auxiliary beams. - Engineering Structures, vol.59, pp.355-374.

Morassi A. and Tonon S. (2008): Dynamic testing for structural identification of a bridge. - J. Bridge Eng., vol.13, No.6, pp.573-585.

Moreno Delgado R. and S.M. dos Santos R.C. (1997): Modelling of railway bridge-vehicle interaction on high speed tracks. - Vol.63, No.3, pp.511-523.

PN-90/B-03200: Steel structures. Calculations and design

PN-EN 1991-2(2007) EC1: Actions on structures. Part 2: loads on Bridges 
Pyrzowski L. and Skabara I. (2003): Life of the bridge based on the study object in situ on the example of the railway bridge truss - Bridge over the Vistula River Figures News. - Gdansk University of Technology.

Shen-Haw Ju and Hung-Ta Lin (2013): Numerical investigation of a steel arch bridge and interaction with high-speed trans. - Engineering Structures, vol.25, No.2, pp.241-250.

Van Nguyen D., Ki Du Ki and Pennung Warnitchai (2009): Dynamic analysis of three-dimensional bridge-high-speed train interactions using a wheel-rail contact model. - Engineering Structures, vol.31, No.12, pp.3090-3106.

Yang Y. and Yau J. (1997): Vehicle-bridge interaction element for dynamic analysis. - J. Struct. Eng., vol.123, No.11, pp.1512-1518.

Received: August 25, 2014

Revised: March 18, 2015 